\title{
Artist's Statement
}

The arch motif explored the series of images that appear throughout this book is intended to establish a visual metaphor for an entrance into areas of academic inquiry imbued with the complexity found in educationalization. While this metaphor remains constant throughout all the images, the specific architectural context of the arch motif in each image has the capacity to set forth iterations unique to the individual elements present. The religious, secular, public, private, and academic sites found in these images provide contextual layers for reflection, but, for many viewers, it may be the juxtaposition of elements in the compositions that provide the most informative platforms for creating meaning in relation to the topics explored in these writings.

The interaction between lintels and arches may prompt the viewer to consider the extent to which the relationship between these differing methods of spanning structural fenestrations was a purposeful synectic contrast or an intended synthetic confluence. Similarly, the interaction between intersecting arches that result in ambiguous shapes caused by low illumination levels raises observational questions relating to the role of alignment in perception as well as reconstructive questions concerning the amount of data required to articulate with accuracy the features of existing forms with reduced visual input. The root metaphor of the arch is thus offered not as an illustration of content but as a prompt for active consideration of the directions in which educationalization is currently being explored. Indeed, it is the active engagement with individually identified visual elements that is the intended focus of each image as well as the overall heuristic goal of the choices made in selecting the photographs. The wide range of juxtapositions resulting in apparent contrasts and others that result in ambiguity are focused on providing flexible visual cues for the reader to reflect on the topics explored by the authors of the chapters in this volume. 
The image entitled arched inclinations above is a photograph taken at the Episcopal Cathedral Church of Saint John the Divine in New York City. The images intersecting portals observed and leaving aligned vaults are depictions of religious and secular spaces at Mont-Saint-Michel in Normandy, France. The photograph time records movement is part of an in-progress series of images depicting the preservation of architectural artefacts at Guildwood Park in Toronto, Ontario. The photograph brackets create space was created at University College, University of Toronto.

Alan R. Wilkinson

Kingston, ON

December 2018 